\title{
P- Delta Effect in Reinforced Concrete Structures of Rigid joint
}

\author{
Yousuf Dinar ${ }^{1}$, Samiul Karim ${ }^{2}$, Ayan Barua ${ }^{2}$, Ashraf Uddin ${ }^{3}$ \\ ${ }^{1,2}$ Graduate Student, Department of Civil Engineering, University of Asia Pacific, Bangladesh \\ ${ }^{3}$ Student, Department of Civil Engineering, University of Asia Pacific, Bangladesh
}

\begin{abstract}
Popularity of High-Rise structures of rigid joint frame system are incresing day by day to accommodate growing people in metropoliton city and to construct the structures without any special structural component. However combination of rigid frame with RC structure get 30 storey as maximum storey and prone to collapse under severe displacement, axial force and moment, if the $P$ Delta effects does not included in analysis and design phase. Due to complexity and low knowledge of $P$-Delta analyses designers, engineers and architectures are prone to perform Linear Static analysis which may eventually become a cause of catastropic collapse of the high-rise. 12 cases and 2 different analysis are performed to give a light on the P-Delta effect in RC Structures of Rigid Joint which will aware and suggest concering person to understand, make experience and perform P-Delta analysis of the high-rise for safety using numeriacal modelling which may accelerate the process and reduce the complexities.
\end{abstract}

Keywords: High-Rise, Rigid joint, RC structures, P-Delta effects, Numerical modeling

\section{INTRODUCTION}

In the U.S., the National Fire Protection Association defines a high-rise as being higher than 75 feet $(23$ meters), or about 7 stories while Most building engineers, inspectors, architects and similar professions define a high-rise as a building that is at least 75 feet $(23 \mathrm{~m})$ tall. High-rise is the demand of new era as it provides accommodation to a well number of people in a small place but without proper design and consider catastrophic may happen which is evident from last few decades after introduction of high-rise and mega city concept Figure 1. Reinforced Concrete structures are prone to effected by several parameters for its self-weight and frame system
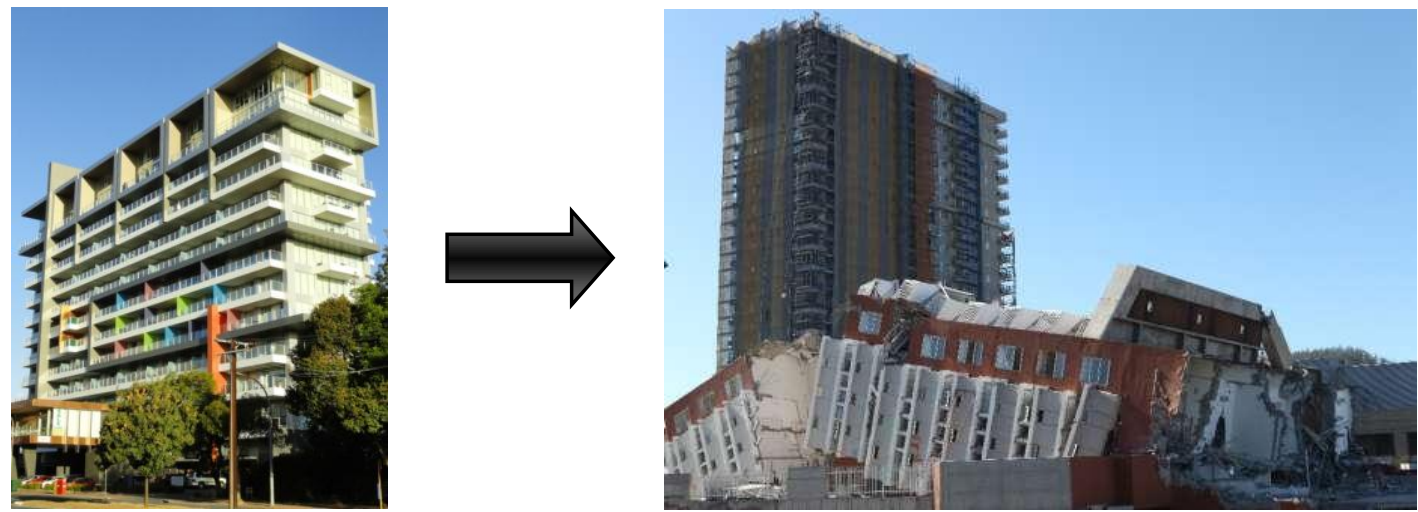

Figure 1: High-rise RC structures may collapse for faulty and inattentive design

Photo Credit: Online (weekendnotes.com)

P-Delta effect is a major issue which affects the structural response severally, neglected for its complexity in analysis phase of the design. Although the development of knowledge and advancement of technology is quite advanced today, there are a very few practical experimental studies on the P- Delta effects of the structure. The most used structural analysis for reinforced concrete design is linear static analysis, where PDelta effect is omitted which is very important to include in analysis and design phase. Because of that, high rise structures may show potential vulnerability against lateral loads. Lacking of proper consideration pushes the RC structures, most constructed structure, to the uneconomical condition by constructing shear wall and bracing or vulnerable state ready for collapse for buckling. P-Delta analysis may bring the $2^{\text {nd }}$ order loading effects in the structure and design the structure with its effects. This analysis is no more a matter of time consuming paper 
work but easy and simple which could be performed by engineers and researchers. Now- a-days many software have the capability to analysis and design with P-Delta effects. All need to is the variation of outcomes such as axial, moment and deflection, between P-Delta and Linear Static analysis to identify when the P-Delta analysis will be performed, possible differences, performing procedure and designing techniques, and this the point from which the idea of this study evolves.

The objective of this study is determined and presents the P-Delta effects in Reinforced Concrete Structures of rigid joint, with respect to structural response, against loads, which is axial, moment and displacement of the structure. Rigid joint is a type of frame system where structure is built with column and beam joint so, sometimes it is known as column- beam joint frame system. This frame system is easy to build and found everywhere till structure of 30 storey. To evaluate the P-Delta effect it is required to perform the linear Static analysis simultaneously. To perform the analysis StaadPro V8i is used for all models of each case. Gradual increasing the height from storey 5 to storey 30 in 5 storey intervals may draw a significant understanding in the trend of the P-Delta effects. After comparing the performance of RC structure with respect to axial, moment and displacement between two mentioned analysis above, necessity of P-Delta analysis over Linear Static analysis and variation of outcomes will be understood clearly. Force unit is KN while displacements are measured in $\mathrm{mm}$.

\section{METHODOLOGY}

In the traditional first order analysis of structures, the effects of change in the structure actions due to structure deformations are neglected. However, when a structure deforms, the applied loads may cause additional actions in the structure that are called second order or P-Delta effects. The P-Delta effect is dependent on the applied load and building characteristics. According to A.S. Moghadam and A. Aziminejad, parameters such as height and stiffness of a building, the degree of its asymmetry may also be of importance ${ }^{[1]}$. So it is necessary to perform P-Delta during analysis of high-rise structures as those are prone to damage under various reason for faulty analysis and design which may happened by not considering any of the parameters. So, P-Delta and other analysis related to high-rise should be performed exactly according to code.

As earlier stated P-Delta is an $2^{\text {nd }}$ order loading considering analysis which is required for slender column consisting structures, Slender structure as a whole, Steel structure for preventing collapse and heavy dead load consisting structures. So it is useful to show the changing outcomes of structures by increasing height making the building slender while considering P-Delta analysis. To identify the loads increasing tendency axial load in a specific column need to be observed for all cases. It will eventually help to understand the design variation for column. On the other side, moment of column have to counted for search the moment changing trend of the column which may help to caution for the building components during design and decrease the displacement evolved from lateral loads. Displacements are accounted because of understanding the priority of P-Delta analysis against Linear Static analysis for the high-rises. For rigid joint structures excessive displacement in a particular frame may cause serious changing the whole structure during lateral events so displacement in exterior beam-column joint is taken to present the severity among the engineers, researchers and authorities. The comparison of the results of two analyses with and without P-Delta will illustrate the magnitude of the P-Delta effects. A well-designed building usually has well-conditioned level by level stiffness/weight ratios. The changes in displacements and member forces are less than $10 \%$. As rigid joint RC frame has no specialized structural component which makes the model simple and easy to evaluate the slenderness effects with increasing loads with additional storey. Study is restrained till storey 30 because of limitation of rigid joint frame system which is mentioned by Dr.Hal S. Iyengar ${ }^{[2]}$ Figure 2.

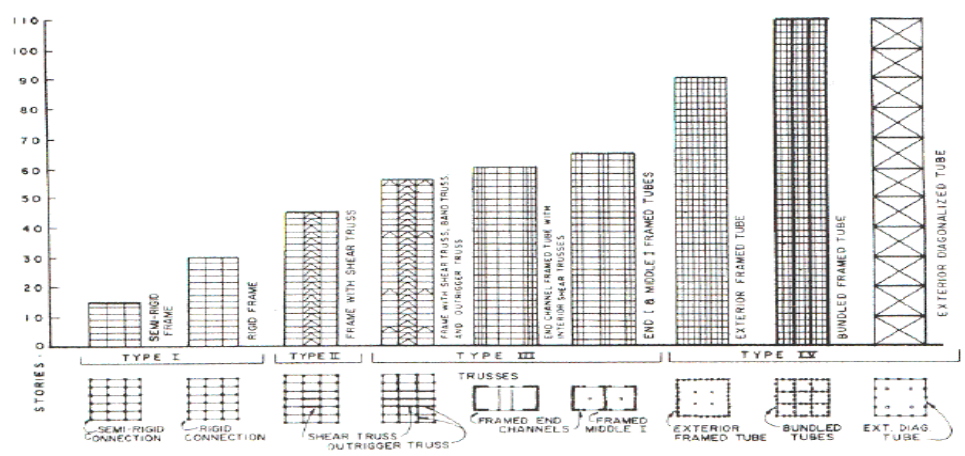

Figure 2: Structural System 


\section{LITERATURE REVIEW}

During seismic event or wind load high-rise building may shake and the utmost exterior columns are subjected to fluctuating axial force both in compression and tension. The lowest part of the column is most conserving highest intensity of axial loads. Story drift in lateral direction due to the lateral load and axial force causes the $2^{\text {nd }}$ order loading effects known as "P-Delta effects" shown in Figure 3 represented by M. A. A. Mollick (1997) ${ }^{[3]}$. MacGregor and Hage (1977), M.A.A Mollick (1997), Chang and Breen (1981), Gaiotti and Smith (1989) and Shimazu and Mollick (1991) have their analytical studies on the P-Delta effects whereas numerical modeling has been done after development of the softwares. A.S. Moghadam and A. Aziminejad (2004), Wiryanto Dewobroto (2011) have presented different way of P-Delta analysis while considering torsion, manual analysis, analytical equation but do not line in the differences of P-Delta and linear Static analysis and guide the height limitation of Linear Static analysis method by presentation of Rigid joint RC structure. The necessity of having a paper which represents P-Delta effects of RC rigid frame structures in simple words for easy understanding pushed to have this study.

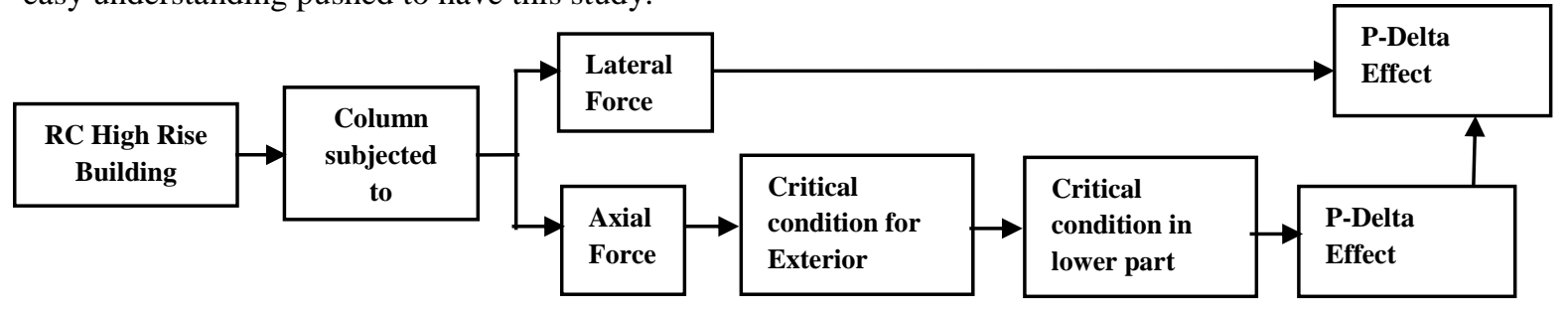

Figure 3: P-Delta effects to total loads

So, This study identify the effects and its trend of changing in terms of axial, moment and deflection of $\mathrm{RC}$ structures using StaadPro and compares to the Linear Static outcomes to give a general understanding of range where P-Delta effects governs significantly.

\section{DESCRIPTION OF P-DELTA ANALYSis}

Geometric stiffness matrix is an approach to include secondary effects in the static and dynamic analysis whereas, in Civil Structural Engineering it is commonly referred to as P-Delta Analysis that is based on a more physical approach. For example, in building analysis the lateral movement of a story mass to a deformed position generates second-order overturning moments. This second-order behavior has been termed the P-Delta effect since the additional overturning moments on the building are equal to the sum of story weights "P" times the lateral displacements "Delta". Many techniques have been proposed for evaluating this second-order behavior and takes place in two steps where linear static only consider one $1^{\text {st }}$ order loading stage Figure 3 . Many researchers, engineers tried to describe the phoneme in simple way.

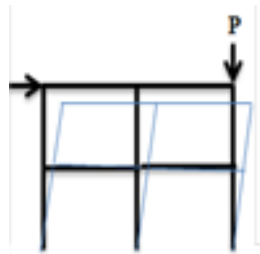

(a) Linear Static

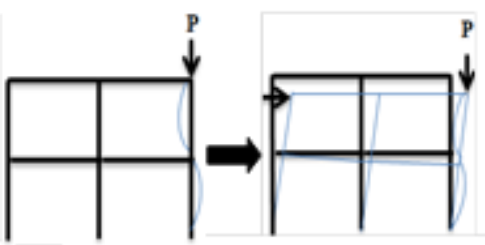

(b) P-Delta Analysis

Figure 3: (a) Linear Static analysis is performed in one step (b) P- Delta analysis is performed in two steps

In short, P-Delta is secondary order loading effect in structure directly related to stiffness as it reduces the stiffness of structural elements. The analysis procedures used to determine P-Delta effects vary from one software to another. Several methods of accommodating P-Delta effects in analysis have been developed. Some of these methods rely on a constrained problem or set of conditions, and will therefore have documented "limitations"; the critical issue is to understand the differences and be aware of the limitations and conditions. Analysis models are "modeling" of the real condition and only provide approximations simulation of the real world. Again, the P-Delta effect does not distinguish between directions and types of loading. It does not have idea about floors, floor levels, or the difference between a column and a beam. Proper care should be taken to work within the limitations of the analysis. By StaadPro, leading structural engineering software, complete effects could be identified using appropriate command. In StaadPro, a unique procedure has been adopted to incorporate the P-Delta effect into the analysis. The procedure consists of the following steps: 
1. First, the primary deflections are calculated based on the provided external loading.

2. Primary deflections are then combined with the originally applied loading to create the secondary loadings. The load vector is then revised to include the secondary effects.

Lateral loading must be present concurrently with the vertical loading for consideration of the P-Delta effect. The Repeat Load facility has been created with this requirement in mind. This facility allows the user to combine previously defined primary load cases to create a new primary load case.

3. A new stiffness analysis is carried out based on the revised load vector to generate new deflections.

4. Element/Member forces and support reactions are calculated based on the new deflections.

P-Delta effects are calculated for frame members only not for finite elements or solid elements. So outcomes are compares against frame members only.

\section{DESCRIPTION OF MODELS}

As mentioned earlier, to observe the effects of P-Delta in RC rigid joint structure six different storey cases is taken where storey variation starts from storey 5 to storey 30 , boundary limit of rigid joint. Making 5 storey intervals from each makes a gradual but less time consuming analysis. Storey cases are: 5, 10, 15, 20, 25 and 30 Figure 4 while the span is constant, $4 \mathrm{X} 3$ Figure 5.

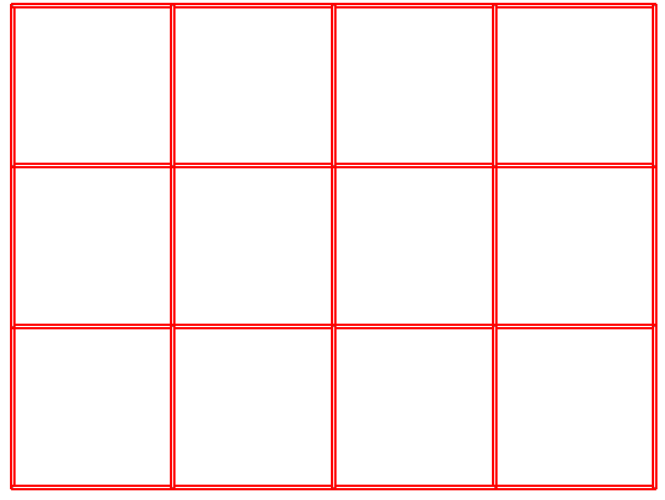

Figure 4: Typical plan of the models

Each of the storey case is performed Linear Static and P-Delta analysis separately with appropriate command. Each storey is 3 metre in height makes Storey 5, Storey 10, Storey 15, Storey 20, Storey and Storey 30 in total height of $15 \mathrm{~m}, 30 \mathrm{~m}, 45 \mathrm{~m}, 60 \mathrm{~m}, 75 \mathrm{~m}$ and $90 \mathrm{~m}$. As storey increases so the slenderness increases. Bay length of buildings in both directions is 5 . The floors are assumed to be rigid in their plane. The lateral load seismic is considered in both directions of the structure using UBC94 by providing seismic coefficient of seismic zone 2, moderate risk rated arena of Bangladesh to perform both Linear Static and P-Delta analysis separately. Accidental load is taken into account for both two major analyses to ensure load eccentricities are considered in analysis. The column sizes are 458X $600 \mathrm{~mm}$ while situated in joint of each beam give compressive strength. On the other hand, slab thickness is $152.4 \mathrm{~mm}$ reinforced concrete of $20 \mathrm{MPa}$ compressive strength. All beams are of same size 406X458 mm of $24 \mathrm{MPa}$ of compressive strength.
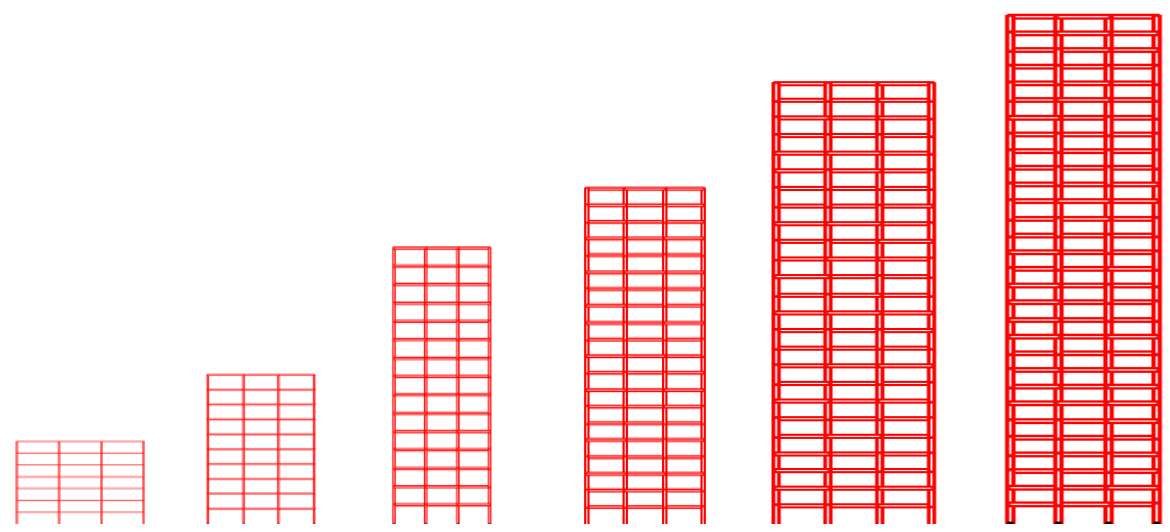

Figure 5: Five different model spans: (a) Storey 5, (b) Storey 10, (c) Storey 15, (d) Storey 20, (e) Storey 25 (e) Storey 30 
The concrete strength is assumed to be $24 \mathrm{MPa}$ with yield strength $414 \mathrm{MPa}$ where Modulus of Elasticity (Young's Modulus) is $248200 \mathrm{MPa}$. The model is assumed to be situated in Dhaka city so seismic zone 2 is taken according to Bangladesh National Building Code $(B N B C)^{[4]}$. Therefore, each column is subjected to both in compression and tension during the shaking in alternative sequence. Higher bending moment governs to the columns due to compression than the tension.

\section{EXPERIMENTAL CASES}

To investigate P- Delta Effect in Reinforced Concrete Structures of Rigid joint six storey group in two different analyses is performed. During study, total 24 models was analyzed and 12 cases, or geometrical possibilities, were simulated through both Linear Static and P-Delta analysis shown in Table I.

The load deformation responses of the numerical model specimens were followed through to failure by means of the deflection in each storey of each case of a particular column. A particular frame, in each and every case with two different analysis procedure, in crucial side of the structure is observed and value taken from it to meet the objectives of the study. A specific column is used for getting axial and moment in each floor.

Table I

Total Cases divided into two separate Analysis Group

\begin{tabular}{|c|c|c|}
\cline { 2 - 3 } \multicolumn{1}{c|}{} & P-Delta Analysis & Linear Static Analysis \\
\hline Storey 5 & Case 1 & Case 7 \\
\hline Storey 10 & Case 2 & Case 8 \\
\hline Storey 15 & Case 3 & Case 9 \\
\hline Storey 20 & Case 4 & Case 10 \\
\hline Storey 25 & Case 5 & Case 11 \\
\hline Storey 30 & Case 6 & Case 12 \\
\hline
\end{tabular}

VII. RESULTS AND DISCUSSIONS

P-Delta and Linear Static analysis of 12 cases, in total 24 models reveals that P-Delta effects significantly influence the axial, moment and displacement of the structural components and get higher value than the Linear Static analysis. The variation particularly identified when the slenderness ratio is comparatively increasing by increasing the storey. Variation is observed in several sections: Variation of axial in an exterior column, Variation of moment in a exterior column displacement in top, variation of storey displacement of PDelta analysis and percentage of variation against slenderness ratio to systematically scrutinize the response characteristics of the structure due to P-Delta effects with respect to slenderness.

\section{A. Variation of horizontal displacement in top:}

All 12 models and 6 storey case are studied to describe how the structure generate difference with height which represent the slenderness and obviously to present the priority of P-Delta analysis over Linear Static analysis. To establish the object top displacement is studied and found that structure analyzed under PDelta effect causes much displacement in top then the structure analyzed by Linear Static analysis. The variation is following a upward trend with increasing storey. Following Figure 6 shows that after P-Delta analysis displacement increased exponentially with increment of storey over the simple analysis, "Linear Static analysis".

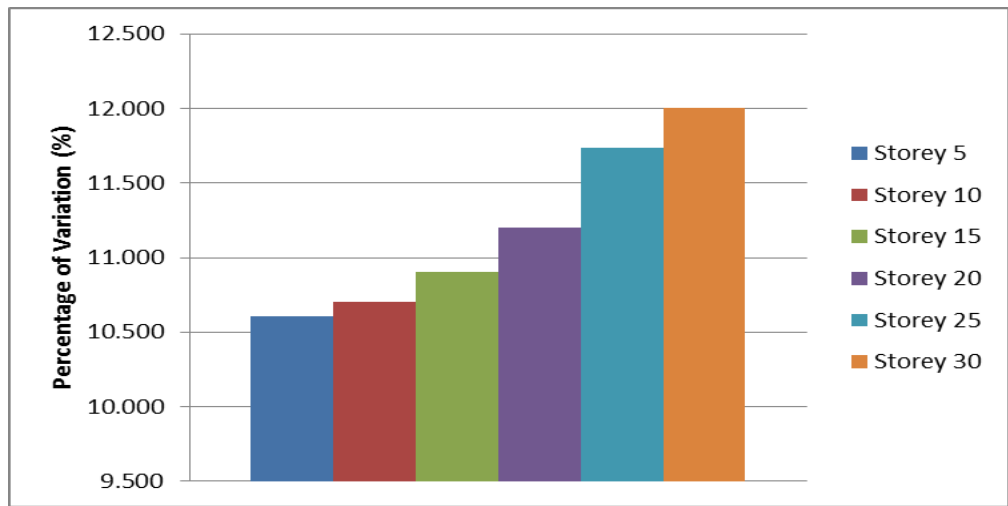

Figure 6: Percentage of variation of displacement in top considered under P-Delta analysis over Linear Static analysis 
Storey Percentage of variation must be seen keeping Linear Static analysis outcomes as base Figure 10. After P-Delta analysis storey 5, storey 10, storey 15, storey 20, storey 25 and storey 30 the top displacement increased by $10.6 \%, 10.7 \%, 10.9 \%, 11.2 \%, 11.73 \%$ and $12 \%$ respectively which represent the the variations do not follow any linear trend. It seems with increasing slenderness variation between Linear Static and P-Delta will be maximized and vice-versa so proper understanding and strategy should be taken when designing a highrise.

\section{B. Story displacement of different storey cases:}

Storey displacements for both types of analysis: P-Delta analysis and Linear Static found maintaining the same trend of increasing with incrementing storey whereas the displacement outcomes of P-Delta analysis is found to be greater that corresponding displacement of Linear Static analysis. This characteristic is found in every storey case and represents the presence of P-Delta effects during performing P-Delta analysis Figure 7 and 8 .

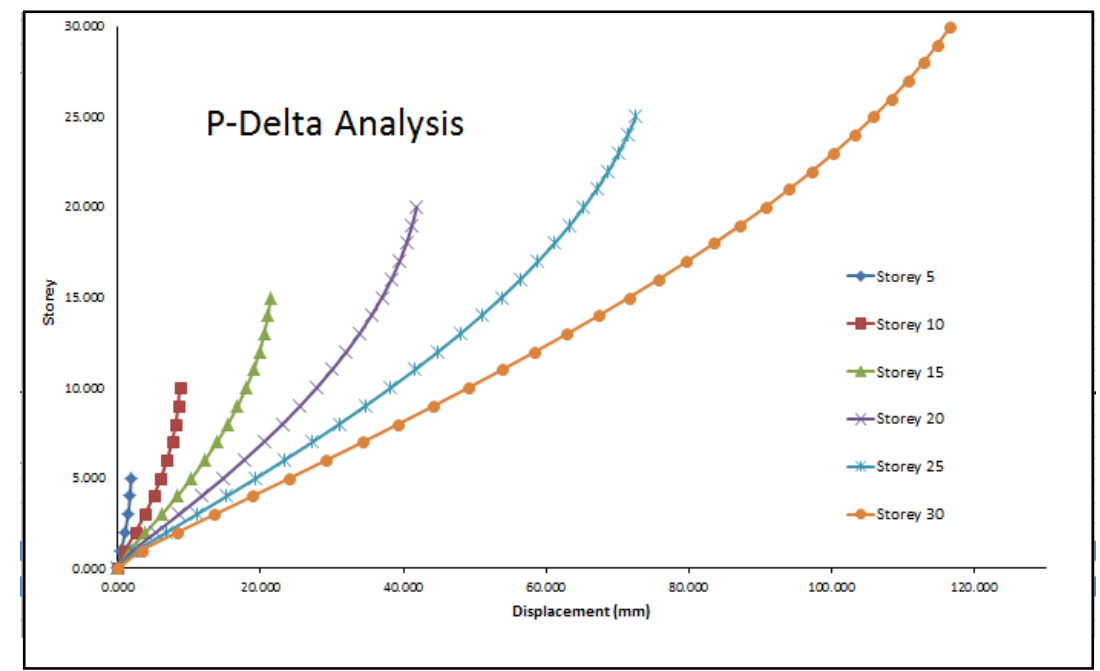

Figure 7: Storey displacement considered for six storey cases under consideration of P-Delta effects

This phenomenon represent that Linear Static consider only the $1^{\text {st }}$ order loading effects which is not realistic for high-rise but P-delta analysis is suitable to get the iterative action as it consider $2^{\text {nd }}$ order loading effects after performing the $1^{\text {st }}$ order loading effects.

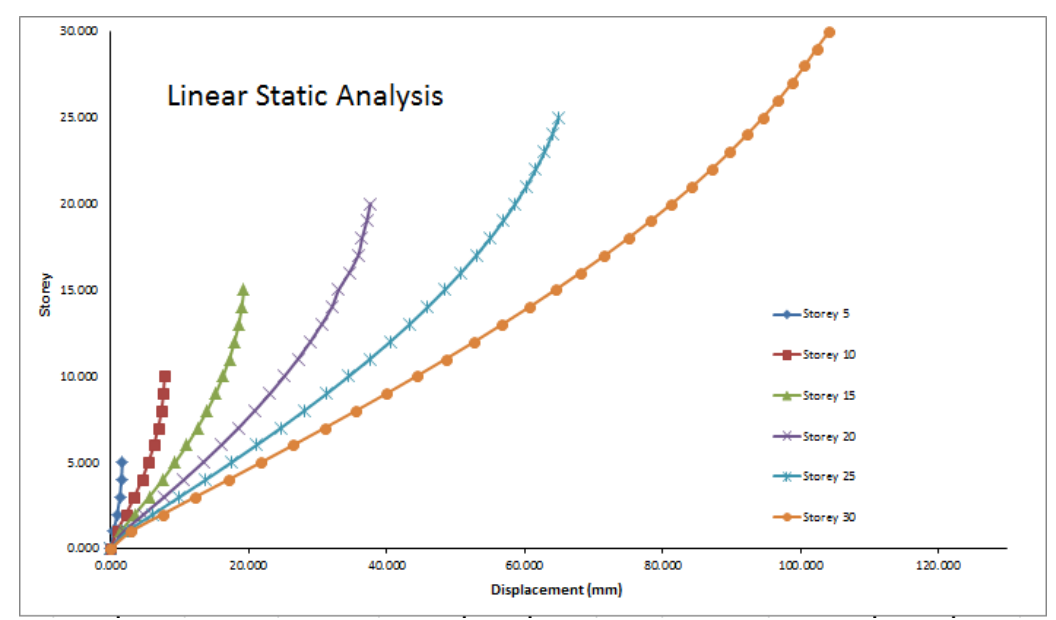

Figure 8: Storey displacement considered for six storey cases under consideration of Linear Static analysis

Maximum displacement is found in top of the storey and it could be mentioned to present the scenario. After P-Delta analysis displacement for storey 5, storey 10, storey 15, storey 20, storey 25 and storey 30 reached to $1.854 \mathrm{~mm}, 8.636 \mathrm{~mm}, 21.361 \mathrm{~mm}, 41.859 \mathrm{~mm}, 72.568 \mathrm{~mm}$ and $116.637 \mathrm{~mm}$ respectively, from $1.676 \mathrm{~mm}$, $7.798 \mathrm{~mm}, 19.304 \mathrm{~mm}, 37.643 \mathrm{~mm}, 64.948 \mathrm{~mm}$ and $104.14 \mathrm{~mm}$ respectively. These trends alert the caution to 
use Linear Static analysis for analysis phase of high-rise. With increasing trend it becomes much important than Linear Static and the considering sway effects of P-Delta during analysis becomes basic needs.

\section{Axial force in critical zone of different cases:}

Axial loads are taken from storey 1 of each storey case of each analysis as a maximum axial load is found in that position. Like the displacement trend, here also the P-Delta outcomes over flow the corresponding case of the Linear Static analysis and represent the necessity of P-delta analysis over the Linear Static for reinforced concrete high-rise structures Figure 9.

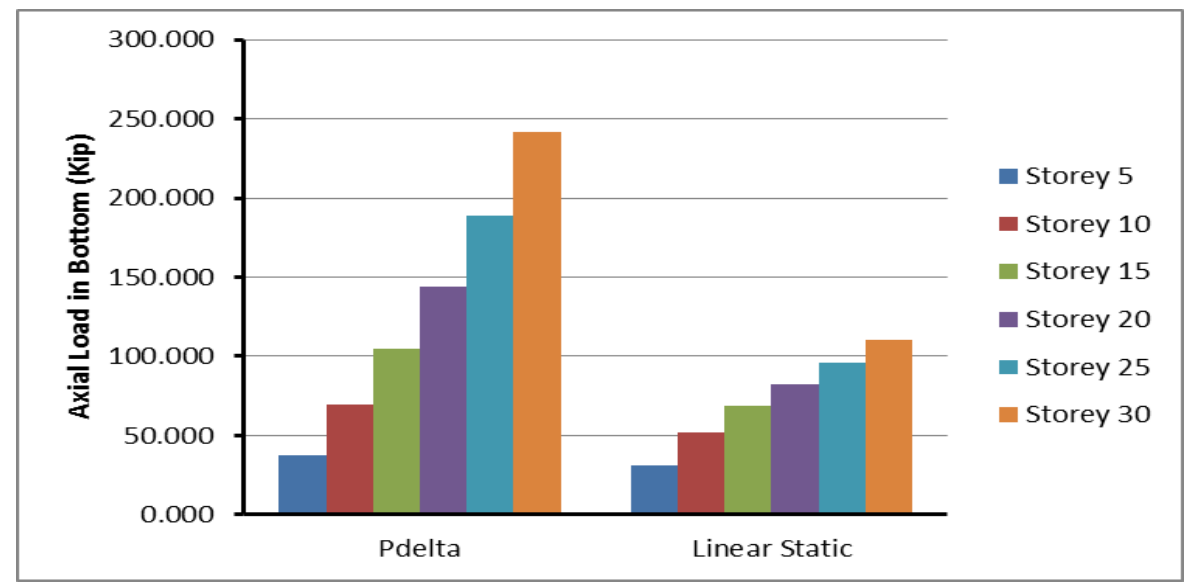

Figure 9: Axial force in critical zone for six storey cases for P-Delta and Linear Static

As the storey increases so the slenderness too which push the difference to positive side and variation maintains an exponential characteristic. For storey 5, storey 10, storey 15, storey 20, storey 25 and storey 30 the variation of axial load from P-Delta analysis against the Linear Static analysis is $18.84 \%, 34.503 \%, 53.023 \%$, $74.16 \%, 96.71 \%$ and $119.1 \%$ respectively. This variation is the main parameter for design too. The section required under P-Delta analysis must be stronger than section designed considering Linear Static only.

\section{Storey Moment of different cases:}

A specific column is observed for observe storey moment of each storey case with two different case: P-Delta analysis and Linear Static analysis. The storey moment trend is different to axial force trend seen in former section. Moment is seem to increase in Linear Static analysis with increment of storey but after consideration of P-Delta effect, the moments are found to be decreasing with increment of height which is not a common trend after all Figure 10.

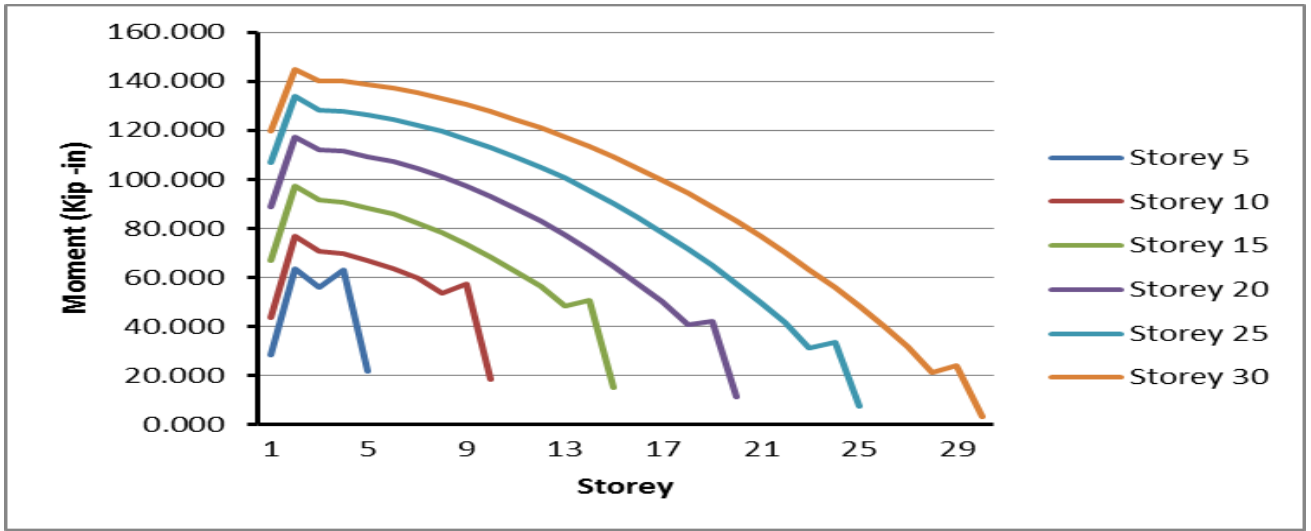

Figure 10: Storey Moment for six storey cases for P-Delta

This structural behaviour let designer think about the axial part properly as that governs the critical situation. However the moments are not so negligible to not count during design. Again the moment increases with increment of storey so slenderness has a effects to the moment. As our structural frame was $4 \mathrm{X} 3$ in plan which is 20 meter by 15 meter, may has its significant role in the moment characteristics. Further addition or substation may change the trend significantly. Observing the P-Delta outcomes a significant property is seen which a region where moments decreases with increasing storey gives a steady decreasing path Figure 11. 


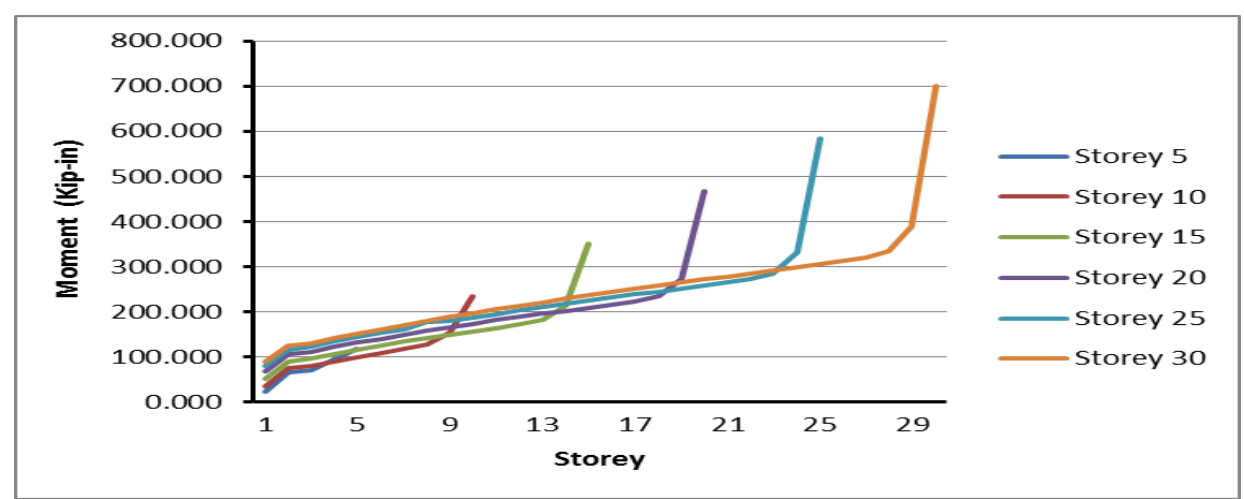

Figure 11: Storey Moment for six storey cases for Linear Static

This path covers $85-90 \%$ of the total path. This steady path increases in length with increasing height or addition of storey. On the other side, analysis conducted without considering P-Delta effects leads to increment of moment with increment of storey as it was expected. Overall high-rise shows higher value then low-rise construction under this analysis.

\section{CONCLUSION}

In Conclusion, it could be summarized that analyzing and designing RC high-rise structure needs expert observation and understanding. Analysis found was versatile in characteristics but it could be said, displacement varies exponentially under P-Delta analysis with increasing height or increment in storey and so the axial force too. Axial force changes in positive side rapidly over the Linear Static analysis, if P-Delta is performed to find it. Moments shows different tendency which is decreasing in value with increment of story or increasing height push to consider axial and displacement most. So, Linear Static and P-Delta both are necessary for RC structures and have to use after proper understanding to prevent any catastrophic. Axial and displacement could be observed by P-Delta analysis while keeping the moment section to the Linear Static analysis. All these outcomes were for reinforced concrete structure of rigid joint which is very common in society. However how the bracing, infill, shear wall and composite section influence the effects of P-Delta could be studied to find out the general trend of those frame system.

\section{Acknowledgements}

The present authors, Yousuf Dinar, Samiul Karim, Ayan Barua and Ashraf Uddin thank the Department of Analysis and Design, ATI Training and Consultants, Dhaka, Bangladesh encouraging and sharing strategy for conducting the simulation work relating to P-Delta Analysis. The authors sincerely thank Mr. Shahin Mahmud, Director, ATI Training and Consultants, Bangladesh for continuous guidance during study.

\section{REFERENCES}

[1] Moghadam A.S., Aziminejad A., (2004), "Interaction of Torsion and P-Delta Effects in Tall Buildings", Proceedings, 13th World Conference on Earthquake Engineering, Vancouver, B.C., Canada., Paper No. 799

[2] Iyengar, H.S., (1972),“ Preliminary Design and Optimization of Tall Buildings”, Proceedings, International Conference on Tall Buildings, Lehigh University., Vol. II.

[3] Mollick, M.A.A., (1997), “Journal of Civil Engineering”, The Institute of Engineers, Bangladesh, Vol. CE 25, No. 2, 1997

[4] BNBC (2006) Bangladesh National Building Code, Housing and Building Research Institute, Mirpur, Dhaka, Bangladesh. 